\title{
Trolox reduces the effect of ethanol on acetylcholine-induced contractions and oxidative stress in the isolated rabbit duodenum
}

\author{
Diego S. Fagundes, Sergio Gonzalo, Laura Grasa, Marta Castro, M. a Pilar Arruebo, Miguel Ángel Plaza \\ and M. ${ }^{a}$ Divina Murillo
}

Departamento de Farmacología y Fisiología (Fisiología). Facultad de Veterinaria. Universidad de Zaragoza. Zaragoza, Spain

\begin{abstract}
Trolox is a hydrophilic analogue of vitamin $\mathrm{E}$ and a free radical scavenger. Ethanol diminishes the amplitude of spontaneous contractions and acetylcholine (ACh)-induced contractions in rabbit duodenum. The aim of this work was to study the effect of trolox on the alterations induced by ethanol on contractility and lipid peroxidation in the duodenum. The duodenal contractility studies in vitro were carried out in an organ bath and the levels of malondialdehyde and 4-hydroxyalkenals (MDA+4-HAD) were measured by spectrophotometry. Trolox increased the reduction induced by ethanol on the amplitude of spontaneous contractions in longitudinal muscle but not in circular muscle. Trolox $4 \mathrm{mM}$ decreased the effects of ethanol on ACh-induced contractions and on MDA+4-HDA concentrations. We conclude that trolox might prevent oxidative stress induced by ethanol in the duodenum.
\end{abstract}

Key words: Trolox. Ethanol. Contractility. Lipid peroxidation. Duodenum. Rabbit.

Fagundes DS, Gonzalo S, Grasa L, Castro M, Arruebo MA, Plaza MA, Divina Murillo M. Trolox reduces the effect of ethanol on acetylcholine-induced contractions and oxidative stress in the isolated rabbit duodenum. Rev Esp Enferm Dig 2011; 103: 396-401.

Acknowledgements: This work was funded by a grant from Ministerio de Ciencia y Tecnología de España (DGI, AGL2006-04317, and ERF) and the Gobierno de Aragón (B61/2009). Fagundes, D.S. received support from the Grupo de Investigación Consolidado del Gobierno de Aragón (B61/2008), Spain.

Note: This work was presented, in part, at the LXVII Congreso Anual de la Sociedad Española de Patología Digestiva (SEPD), Sitges (Barcelona, Spain), June 2008.

Received: 10-01-11.

Accepted: 18-03-11.

Correspondence: Divina Murillo. Departamento de Farmacología y Fisiología (Fisiología). Facultad de Veterinaria. Universidad de Zaragoza. C/ Miguel Servet, 177. 50013 Zaragoza, Spain.

e-mail: dmurillo@unizar.es

\section{INTRODUCTION}

Alcohol is a hydroxyl compound that can be present in the diet. The amount and type of alcohol consumed and the frequency of its consumption can vary tremendously and can have divergent effects on an organism $(1,2)$. The deleterious effects of alcohol, at least partly, involve alcohol induced oxidative injury that has been documented by measurement of oxidant radicals (3-5). The organism has developed a complex defense system which is composed of free radical scavenger molecules such as vitamins and antioxidative enzymes.

Ethanol induces inhibition of esophageal, gastric and intestinal contractility (6-9). The inhibition produced by ethanol is attributed to an inhibition of $\mathrm{Ca}^{2+}$ influx in the canine jejunal circular muscle and in human and cat esophageal contractility $(7,8)$. Alcohol also inhibits the motility of the sphincter of Oddi in vitro $(10,11)$ and the colon (12). In a previous study, we demonstrated the inhibitory effects of ethanol on the spontaneous contractions and $\mathrm{ACh}$-induced contractions in rabbit duodenum, which are reduced by $\mathrm{Ca}^{2+}$-activated $\mathrm{K}^{+}$channel antagonists (13). Ethanol also provokes an inhibition of gastric emptying and small intestinal transit that is mediated by type A CCK receptors or capsaicin-sensitive neural pathways (14-16). However, ethanol produces contractile actions in guinea pig gastric smooth muscle, which required extracellular calcium and are blocked by tyrosine kinase inhibitors (17).

Trolox, a phenolic antioxidant, originally designed for food preservation, has a chromane structure similar to atocopherol or vitamin E $(18,19)$. Trolox decreases hepatocellular damage during sepsis (20) and abrogates oxidative stress during cold small bowel storage (21).

Although antioxidants can attenuate alcohol-induced injury, there is no single antioxidant that protects all organs during all modes of exposure (3). There is very little documentation available on the effect of trolox on intestinal motility. In addition, alcohol induces oxidative stress and 
reduces vitamin E levels (22). The aim of this work was to study the effect of trolox on duodenal alterations induced by ethanol on acetylcholine-induced contractions and lipid peroxidation.

\section{MATERIALS AND METHODS}

\section{Animals}

Male, New Zealand rabbits, weighing 2-2.5 kg, were fed with standard rabbit food and given free access to water. The rabbits were humanely handled and put down in accordance with European Council Directive 86/609/EEC.

\section{Chemicals}

Acetylcholine (ACh) and 6-hydroxy-2,5,7,8-tetramethylchroman-2-carboxylic acid (trolox, a water soluble analogue of vitamin E) were obtained from Sigma (Madrid, Spain). The other chemicals used were analytical grade. The trolox was dissolved in Krebs solution. All other chemicals were dissolved in distilled water. All solutions were stored at $-20{ }^{\circ} \mathrm{C}$ and fresh dilutions were made daily.

\section{Preparation of duodenal segments}

After $24 \mathrm{~h}$ of fasting, the rabbits were killed and pieces of duodenum were cut into longitudinal and circular smooth muscle segments (10 $\mathrm{mm}$ long and $8 \mathrm{~mm}$ wide). Whole thickness segments were vertically suspended in a thermostatically controlled organ bath containing Krebs solution (in mM: $\mathrm{NaCl} 120, \mathrm{KCl} 4.70, \mathrm{CaCl}_{2} 2.40, \mathrm{MgSO}_{4} 1.20$, $\mathrm{NaHCO}_{3} 24.50, \mathrm{KH}_{2} \mathrm{PO}_{4} 1.00$ and glucose 5.60) at $37{ }^{\circ} \mathrm{C}$ to achieve pH 7.4 and continuously gassed with $95 \% \mathrm{O}_{2}$ and $5 \% \mathrm{CO}_{2}$.

Each segment was connected to an isometric force transducer (Pioden UF1, Graham Bell House, Canterbury, UK). The segments were stretched passively to an initial tension of $20 \mathrm{mN}$. The signal output of mechanical activity was amplified (The MacLab Bridge Amp, AD Instruments Inc, Milford MA, USA) with a range of $2 \mathrm{mV}$. Mechanical activity was observed and recorded for further analysis using the MacLab Systems software. The segments were allowed to equilibrate in Krebs solution for $45 \mathrm{~min}$ before use.

\section{Experimental protocols}

Each experimental protocol was systematically performed on 4 longitudinal and 4 circular muscle segments taken from the same rabbit and repeated in three or four animals. Segments that did not show spontaneous activity were discarded; in this way, each preparation served as its own control. The protocol of the experiments was as fol- lows: after the adaptation period of $45 \mathrm{~min}$, the spontaneous contractions of the duodenum and the $\mathrm{ACh}(0.1 \mathrm{mM})$ responses were recorded in Krebs solution and considered as the control responses. Ethanol (at the doses of 56.2, 114.5 or $170.4 \mathrm{mM}$ which are equivalent to $2.58,5.27$ or $7.85 \mathrm{~g} / 1$ respectively) was then added to the bath for $90 \mathrm{~min}$ and then a second $\mathrm{ACh}(0.1 \mathrm{mM})$ response was evoked. This second response was compared with the control and expressed as percentage.

To study the effect of trolox on the ethanol alterations, trolox (1.2 and $4 \mathrm{mM}$ ) was added to the bath $15 \mathrm{~min}$ before the ethanol $(56.2,114.5$ or $170.4 \mathrm{mM})$.

\section{Malondialdehyde (MDA) and 4-hydroxyalkenals (4-HDA) quantitation}

The tissue concentrations of MDA and 4-hydroxyalkenals (MDA+4-HDA) were used as an index of lipid peroxidation (23). Tissue samples were incubated at $37^{\circ} \mathrm{C}$ in the same conditions as organ bath studies and were divided into the following experimental groups: control (Krebs solution), ethanol, Trolox, and Trolox plus ethanol. After incubation, the tissues were frozen in isopentane for MDA+4HDA analysis. The tissues were homogenized in ice-cold Tris buffer ( $50 \mathrm{mM}, \mathrm{pH} 7.4)$ and were centrifuged at 3000 $\mathrm{x} \mathrm{g}$ for $10 \mathrm{~min}$ at $4{ }^{\circ} \mathrm{C}$. In the assay, MDA+4-HDA reacts with N-methyl-2-phenylindole, yielding a stable chromophore with maximal absorbance at $586 \mathrm{~nm}$; 1,1,3,3tetramethoxypropane was used as a standard. Results were expressed as nmol MDA+4-HDA mg-1 of protein. Protein concentration was determined by the Bradford method (24), using bovine serum albumin as a standard.

\section{Analysis of data}

The integrated mechanical activity per second (milliNewtons per second, $\mathrm{mN} \mathrm{s}^{-1}$ ) was quantified as the integrated area per second during the first 3 min of $\mathrm{ACh}$ response, minus the integrated area per second of spontaneous motility, 3 min before adding $\mathrm{ACh}$ to the bath, and normalized per square millimeter of cross-sectional area $\left(\mathrm{CSA} ; \mathrm{mm}^{2}\right)(13,25)$. The amplitude and frequency of the spontaneous contractions were analyzed. Mean amplitude (in $\mathrm{mN}$ ) of contractions was calculated as the average of peak-to-peak differences over $5 \mathrm{~min}$. The frequency of contractions was expressed as the contractions per minute (cpm) over a 5 min period. The amplitude and frequency of spontaneous contractions in the presence of substances was expressed as a percentage of the values in the absence of substances (control period). Values are expressed as mean \pm SEM. Means were compared using one-way variance analysis (ANOVA) tests and p-values determined using the Scheffé $F$ test for organ bath studies and Fisher test for MDA+4-HDA. Differences with $\mathrm{p}$-values $<0.05$ were considered statistically significant. 


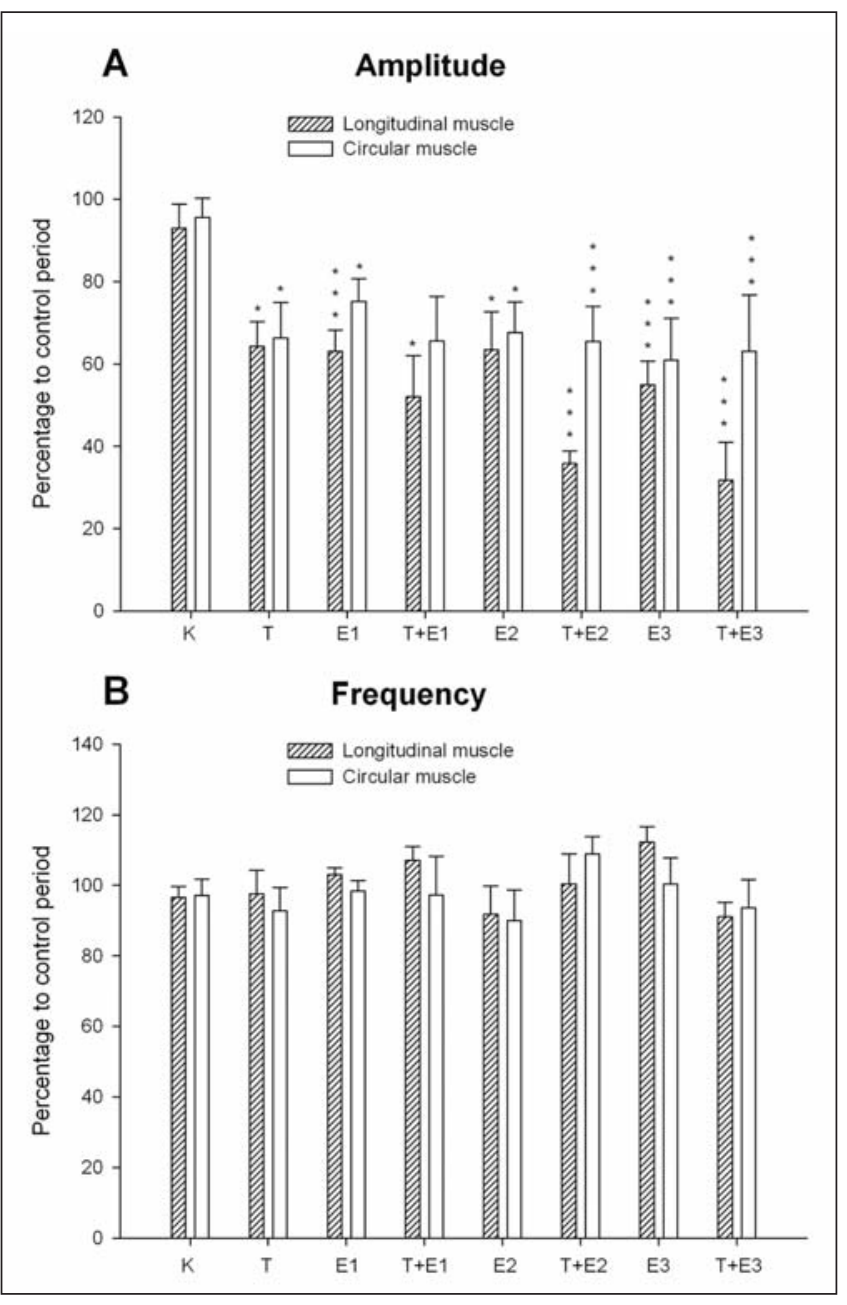

Fig. 1. Amplitude (A) and frequency (B) of spontaneous contractions from longitudinal and circular muscle of rabbit duodenum in different conditions: Control (K, Krebs), or ethanol $56.2 \mathrm{mM}$ (E1), $114.5 \mathrm{mM}$ (E2) and $170.4 \mathrm{mM}$ (E3) during $90 \mathrm{~min}$. Trolox $4 \mathrm{mM}$ added $15 \mathrm{~min}$ before Krebs (T) or ethanol $56.2 \mathrm{mM}(\mathrm{T}+\mathrm{E} 1), 114.5 \mathrm{mM}(\mathrm{T}+\mathrm{E} 2)$ and $170.4 \mathrm{mM}(\mathrm{T}+\mathrm{E} 3)$. Values are the mean \pm S.E.M of 8 segments (\% of control period). ${ }^{*} p<0.05,{ }^{* *} p<0.01$ and ${ }^{* * *} p<0.001$ with respect to the control period.

\section{RESULTS}

The spontaneous motility of isolated rabbit duodenum was rhythmic and cyclic. The amplitude of contractions was $19.3 \pm 2.3 \mathrm{mN}$ and $2.4 \pm 0.5 \mathrm{mN}(\mathrm{n}=12)$ and the frequency of contractions was $13.5 \pm 0.4 \mathrm{cpm}$ and $10.7 \pm 0.5$ $\mathrm{cpm}(\mathrm{n}=12)$ in longitudinal and circular smooth muscle of duodenum respectively, in control conditions.

Ethanol $(56.2,114.5$ and $170.4 \mathrm{mM})$ diminished the amplitude of spontaneous contractions but did not modify the frequency of contractions in longitudinal and circular muscles of the duodenum (Figs. 1A and 1B). The AChinduced contractions $(0.1 \mathrm{mM})$ were significantly reduced by ethanol at three concentrations tested in both types of smooth muscle of the duodenum (Fig. 2A).
Trolox, a water-soluble vitamin $\mathrm{E}$ analogue, diminished the amplitude of spontaneous contractions in longitudinal (at $4 \mathrm{mM}, 36 \%$ vs. control) and circular (at $4 \mathrm{mM}, 34 \%$ vs. control) muscles of the duodenum (Fig. 1A). In contrast, the frequency of spontaneous contractions (Fig. 1B) and the ACh-induced contractions $(0.1 \mathrm{mM})$ were not altered (Fig. 2A). When trolox was added to the bath $15 \mathrm{~min}$ before ethanol it increased the reduction induced by ethanol on the amplitude of spontaneous contractions in longitudinal muscle but not in circular muscle (Fig. 1A).

Trolox (1.2 mM), administered before ethanol, reverted the effect of the lowest concentration of ethanol on AChinduced contractions in longitudinal muscle of duodenum $(107.8 \pm 12.5 \% \mathrm{n}=8 ; 67.3 \pm 12.5 \% \mathrm{n}=8 ; 75.7 \pm 7.2 \% \mathrm{n}$ $=8$; vs. control $100 \%$ at $56.2,114.5$ and $170.4 \mathrm{mM}$ of ethanol respectively). Trolox (1.2 $\mathrm{mM})$ did not revert the ethanol effect in circular muscle $(90.6 \pm 7.5 \% \mathrm{n}=8 ; 77.1$ $\pm 8.2 \% \mathrm{n}=8 ; 54.0 \pm 17.2 \% \mathrm{n}=8 ; v s$. control $100 \%$ at 56.2 , 114.5 and $170.4 \mathrm{mM}$ of ethanol respectively). However, trolox $(4 \mathrm{mM})$ antagonized the inhibition induced by ethanol on ACh-induced contractions in longitudinal and circular muscles of the duodenum (Fig. 2A).

Ethanol (56.2, 114.5 and $170.4 \mathrm{mM})$ increased, in a concentration-dependent manner, the MDA+4-HDA concentrations with respect to Krebs in homogenates from duodenum. Trolox (4 mM) decreased MDA+4-HDA levels induced by 114.5 and $170.4 \mathrm{mM}$ ethanol concentrations in the duodenum (Fig. 2B).

\section{DISCUSSION}

There is evidence that alcohol can damage or alter the function of different organs. The organs that have high metabolism, such as the liver, pancreas or stomach, are more susceptible to injury $(6,9,26,27)$. The effect of alcohol in the digestive tract depends on the species of animal used in the research; in the same region it can induce opposite reactions. In gastric smooth muscle it causes inhibition in dogs and cats $(6,9)$, but in guinea pigs, it causes a contraction (17). Our experiments show that ethanol reduces the amplitude of spontaneous contractions in the longitudinal and circular muscles of rabbit duodenum, but it does not modify the frequency of spontaneous contractions. These findings are consistent with previous observations in vitro in canine antral and intestinal smooth muscle $(6,8)$, and in vivo in human jejunal contractile activity (28). $\mathrm{Ca}^{2+}$ triggers contraction in smooth muscle and is a second messenger, transducing signals from neurotransmitters, hormones and growth factors (29). The amplitude and frequency of spontaneous contractions of rabbit duodenum decrease in $\mathrm{Ca}^{2+}$ free medium (30) and similar results have been described in sheep duodenum (31). In a study using intracellular recordings, alcohol acts through mechanisms involving hyperpolarization of membrane and these authors suggest that alcohol exerts its direct effects on jejunal smooth muscle contractility (8). The ethanol-induced inhibition on the 
amplitude of spontaneous contractions in rabbit duodenum is attributed to opening intermediate-conductance $\mathrm{Ca}^{2+}$-activated $\mathrm{K}^{+}$channels (13).

In the current study, ethanol decreased ACh-induced contractions in rabbit duodenum and this accords with other studies in which ethanol has been shown to reduce the contractions produced by $\mathrm{ACh}$ in isolated rat ileum (32), in canine jejunal circular smooth muscle (8) and in rabbit duodenum (13). Furthermore, ethanol decreased the thickness of synaptosomal plasma membrane vesicles lipid bilayer (33).

Trolox is a hydrophilic analogue of vitamin $\mathrm{E}$, is a phenolic antioxidant and has a chromane structure similar to a-tocopherol but without the polyisoprenoid hydrophobic tail $(18,19)$. There is little information about the effect of trolox or vitamin $\mathrm{E}$ on the contractility of gastrointestinal smooth muscle. Previously, we have reported that trolox reduces the amplitude of duodenal spontaneous contractions but it does not alter their frequency (34). In normoxia, addition of a-tocopherol produces no discernible effects on the frequency of contractions in guinea-pig colon (35). Vitamin $\mathrm{E}$ decreases contractions induced by $400 \mathrm{mM}$ of ethanol in isolated canine cerebral vascular rings (36). However, vitamin $\mathrm{E}$ fails to show a protective action of intestinal ischemia in the hamster (37). Our results show that trolox increased the inhibition of the amplitude of spontaneous contractions induced by ethanol in duodenal longitudinal muscle; it had an additive effect on longitudinal muscle but it did not affect the circular muscle neither the frequency of spontaneous movements. The vitamin $\mathrm{E}$ action mechanisms proposed are inhibition of a-tropomyosin or inhibitory action on protein kinase $\mathrm{C}$ or inhibition of scavenger receptors class A $(38,39)$. Perhaps trolox is mediated via excitation contraction coupling pathways of spontaneous contractions and increases the ethanol effect.

Our findings show that trolox did not alter the ACh responses in duodenum. However, trolox antagonized the effect evoked by ethanol on the ACh responses in our experimental model. Vitamin $\mathrm{E}$ does not inhibit the contractions induced by $\mathrm{KCl}$ or prostaglandin $\mathrm{F}_{2 \mathrm{a}}(36)$. Nevertheless vitamin $\mathrm{E}$ protects the bladder from the effects of in vitro hydrogen peroxide (40). Also vitamin $E$ attenuates the contractions produced by alcohol in canine cerebral arterial rings (36). Trolox increased the reduction induced by ethanol on the amplitude of spontaneous contraction but it reverted the inhibition of ACh-induced contractions in longitudinal muscle. These opposite effects of trolox on spontaneous contractions and ACh-induced contractions could be due to different mechanisms of activation. The spontaneous contractions are produced by the depolarization of interstitial cells of Cajal and ACh contractions are evoked by the binding of acetylcholine to muscarinic receptors.

When alcohol is administered acute or chronically, it causes oxidative stress to most tissues (3). Alcohol is metabolized in the liver and the pathways of metabolism produce free radicals that affect the antioxidant system (4). Free radicals alter lipid peroxidation and antioxidants are essential in preventing the cellular damage that they cause $(22,41,42)$.

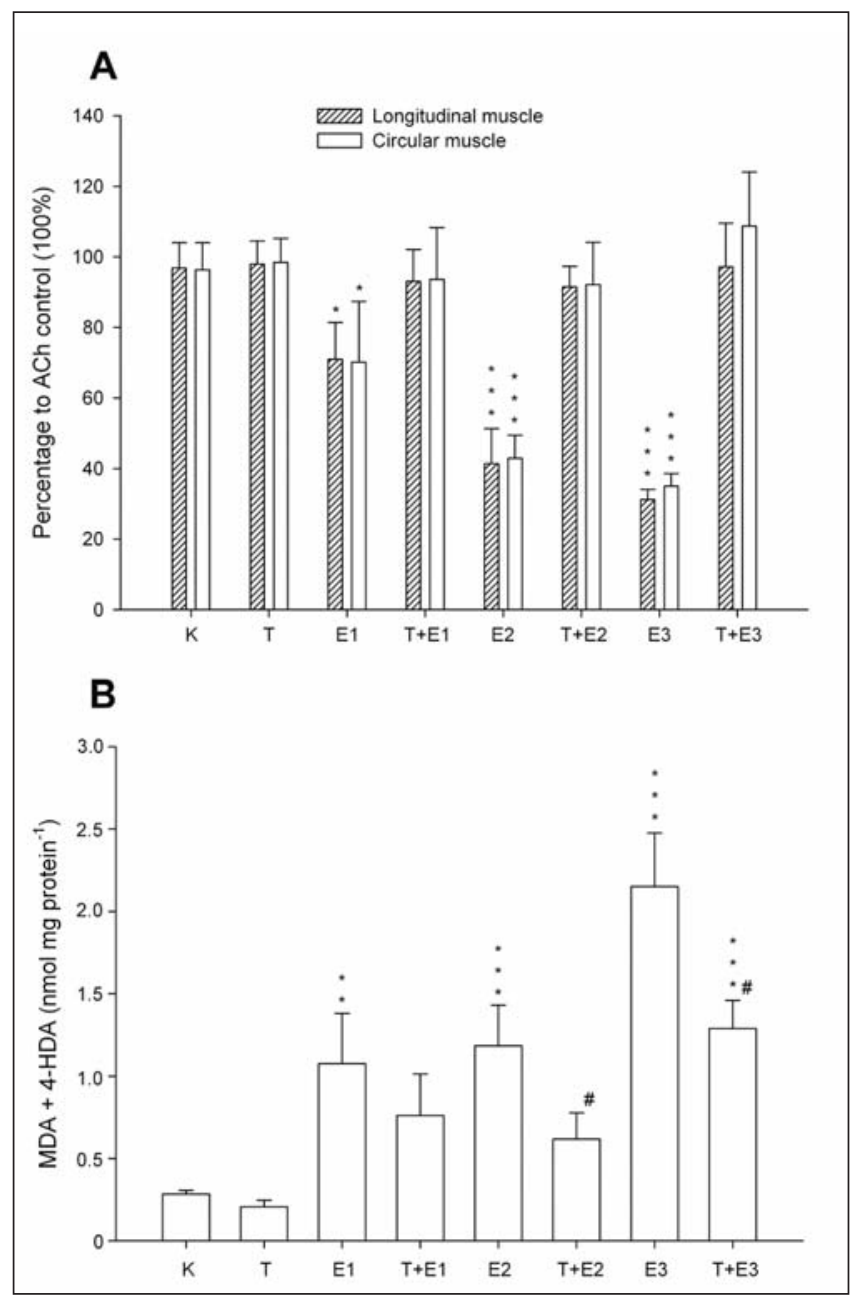

Fig. 2. Effect of ethanol (A) on acetylcholine (ACh)-induced contractions $(0.1 \mathrm{mM})$ from longitudinal and circular muscle of rabbit duodenum and (B) on MDA+4-HDA levels from homogenates of duodenum. Effect of Krebs ( $\mathrm{K}$, control) or Trolox $4 \mathrm{mM}$ (T) during $90 \mathrm{~min}$. Trolox $4 \mathrm{mM}$ added $15 \mathrm{~min}$ before ethanol $56.2 \mathrm{mM}(\mathrm{T}+\mathrm{E} 1), 114.5 \mathrm{mM}(\mathrm{T}+\mathrm{E} 2)$ and $170.4 \mathrm{mM}(\mathrm{T}+\mathrm{E} 3)$. The columns are mean values and vertical bars indicate S.E.M. ${ }^{*} p<0.05$, ${ }^{* *} p<0.01$ and ${ }^{* * *} p<0.001$ with respect to the control period; $\# p<0.05$ with respect to ethanol (at the same concentration).

The biochemical changes elicit by ethanol are also accompanied by an increase in lipid peroxidation and MDA is an indicator of lipid peroxidation (26). Another study shows that ethanol induces lipid peroxidation and reduces vitamin E levels in Guinea pigs (22). Furthermore, it has also been described that oxidative stress alters pig bladder contractility, affecting the muscarinic receptor (43).

In this work, the concentration of MDA+4-HDA was elevated after the incubation of duodenal tissue with ethanol. Trolox reduced this increase in MDA+4-HDA levels and antagonized the effect of ethanol on the ACh-induced contractions. These results indicate that alcohol induced lipid peroxidation, increasing the levels of MDA+4-HDA, that is a marker of oxidative stress (23). Our results coincide with studies in which ethanol treatment has resulted in the deple- 
tion of glutathione levels and decreased antioxidant activity as well as elevating MDA (4). In hepatocytes, the increase in lipid peroxidation induced by ethanol is reversed by vitamin E (26). Trolox enhances cardiac recovery after ischemia/reperfusion, both when it is perfused in vitro and after its oral administration. Vitamin E also favorably affects cardiac recovery, but does so less effectively than trolox. The production of the thiobarbituric acid-reactive substances (TBARS) is significantly inhibited by trolox, suggesting that its beneficial effects are due to its antioxidant activities (44). The combination of vitamin $\mathrm{C}$, vitamin $\mathrm{E}$ and selenium has a protective effect on ethanol-induced duodenal mucosal injury (45). A diet high in vitamin E protects bladder smooth muscle from peroxidation produced by hydrogen peroxide incubation (40). In addition, trolox reduces MDA levels in oxidative stress of mucosal injury during cold small bowel storage (21) and in the incubation of duodenal segments with lipopolysaccharide (34).

We can conclude that trolox reduces the effects of ethanol on ACh-induced contractions and on MDA+4-HDA levels and trolox might therefore prevent oxidative stress induced by ethanol in the duodenum.

\section{REFERENCES}

1. Solera Albero J, Tárraga López PJ, Carbayo Herencia JA, López Cara MA, Celada Rodríguez A, Cerdán Oliver M, et al. Influence of diet and lifestyle in colorectal cancer. Rev Esp Enferm Dig 2007;99(4):190200.

2. Franco A, Sikalidis AK, Solís Herruzo JA. Colorectal cancer: influence of diet and lifestyle factors. Rev Esp Enferm Dig 2005;97(6):432-48.

3. McDonough KH. Antioxidant nutrients and alcohol. Toxicology 2003;189(1-2):89-97.

4. Das SK,Vasudevan DM. Alcohol-induced oxidative stress. Life Sci 2007:81(3):177-87.

5. Conde de la Rosa L, Moshage H, Nieto N. Hepatocyte oxidant stress and alcoholic liver disease. Rev Esp Enferm Dig 2008;100(3):156-63.

6. Sanders KM, Bauer AJ. Ethyl alcohol interferes with excitation-contraction mechanisms of canine antral muscle. Am J Physiol 1982;242(3):G222-30.

7. Keshavarzian A, Zorub O, Sayeed M, Urban G, Sweeney C, Winship $\mathrm{D}$, et al. Acute ethanol inhibits calcium influxes into esophageal smooth but not striated muscle: a possible mechanism for ethanol-induced inhibition of esophageal contractility. J Pharmacol Exp Ther 1994;270 (3): 1057-62.

8. Lu G, Sarr MG, Szurszewski JH. Effects of ethyl alcohol on canine jejunal circular smooth muscle. Dig Dis Sci 1997;42(12):2403-10.

9. Sim SS, Choi JC, Min DS, Rhie DJ, Yoon SH, Hahn SJ, et al. Effect of ethanol on spontaneous phasic contractions of cat gastric smooth muscle. Scand J Gastroenterol 2002;37(1):23-7.

10. Cullen JJ, Ledlow A, Murray JA, Conklin JL. The effect of ethanol on sphincter of Oddi motility in vitro. J Surg Res 1997;67(1):58-61.

11. Sari R, Palvolgyi A, Rakonczay Z, Jr., Takacs T, Lonovics J, Czako $\mathrm{L}$, et al. Ethanol inhibits the motility of rabbit sphincter of Oddi in vitro. World J Gastroenterol 2004;10(23):3470-4.

12. Wang SL, Xie DP, Liu KJ, Qin JF, Feng M, Kunze W, et al. Nitric oxide mediates the inhibitory effect of ethanol on the motility of isolated longitudinal muscle of proximal colon in rats. Neurogastroenterol Motil 2007;19(6):515-21.

13. Fagundes DS, Grasa L, Arruebo MP, Plaza MA, Murillo MD. Ca2+activated $\mathrm{K}+$ channels involved in duodenal dismotility induced by ethanol. Alcohol Alcohol 2007;42(4):291-5.

14. Izbeki F, Wittmann T, Csati S, Lonovics J. The mechanisms of the inhibitory effect of ethanol on gastric emptying involve type A CCK receptors. Regul Pept 2004;117(2):101-5.
15. Izbeki F, Wittmann T, Jancso G, Csati S, Lonovics J. Inhibition of gastric emptying and small intestinal transit by ethanol is mediated by capsaicin-sensitive afferent nerves. Naunyn Schmiedebergs Arch Pharmacol 2002; 365(1):17-21.

16. Franke A, Teyssen S, Harder H, Singer MV. Effect of ethanol and some alcoholic beverages on gastric emptying in humans. Scand J Gastroenterol 2004;39(7):638-44.

17. Zheng XL, Mokashi S, Hollenberg MD. Contractile action of ethanol in guinea pig gastric smooth muscle: inhibition by tyrosine kinase inhibitors and comparison with the contractile action of epidermal growth factor-urogastrone. J Pharmacol Exp Ther 1997;282(1):485-95.

18. Bjorneboe A, Bjorneboe GE, Drevon CA. Absorption, transport and distribution of vitamin E. J Nutr 1990;120(3):233-42.

19. Tafazoli S, Wright JS, O'Brien PJ. Prooxidant and antioxidant activity of vitamin $\mathrm{E}$ analogues and troglitazone. Chem Res Toxicol 2005;18(10):1567-74.

20. Park SW, Lee SM. The beneficial effect of Trolox on sepsis-induced hepatic drug metabolizing dysfunction. Arch Pharm Res 2004;27 (2):232-8.

21. Salehi P, Walker J, Madsen K, Churchill TA. Control of oxidative stress in small bowel: relevance to organ preservation. Surgery 2006;139 (3):317-23.

22. Suresh MV, Sreeranjit Kumar CV, Lal JJ, Indira M. Impact of massive ascorbic acid supplementation on alcohol induced oxidative stress in guinea pigs. Toxicol Lett 1999;104(3):221-9.

23. Esterbauer H, Cheeseman KH. Determination of aldehydic lipid peroxidation products: malonaldehyde and 4-hydroxynonenal. Methods Enzymol 1990;186:407-21.

24. Bradford MM. A rapid and sensitive method for the quantitation of microgram quantities of protein utilizing the principle of protein-dye binding. Anal Biochem 1976;72:248-54.

25. Rebollar E, Arruebo MP, Plaza MA, Murillo MD. Effect of lipopolysaccharide on rabbit small intestine muscle contractility in vitro: role of prostaglandins. Neurogastroenterol Motil 2002;14(6):633-42.

26. Gyamfi MA, Wan YJ. The effect of ethanol, ethanol metabolizing enzyme inhibitors, and Vitamin $\mathrm{E}$ on regulating glutathione, glutathione $\mathrm{S}$ transferase, and S-adenosylmethionine in mouse primary hepatocyte. Hepatol Res 2006;35(1):53-61.

27. Gonzalez A, Pariente JA, Salido GM. Ethanol impairs calcium homeostasis following CCK-8 stimulation in mouse pancreatic acinar cells Alcohol 2008;42(7):565-73.

28. Robles EA, Mezey E, Halsted CH, Schuster MM. Effect of ethanol on motility of the small intestine. Johns Hopkins Med J 1974;135(1):17-24.

29. Farrugia G. Ionic conductances in gastrointestinal smooth muscles and interstitial cells of Cajal. Annu Rev Physiol 1999;61:45-84.

30. Grasa L, Rebollar E, Arruebo MP, Plaza MA, Murillo MD. The role of $\mathrm{Ca} 2+$ in the contractility of rabbit small intestine in vitro. J Physiol Pharmacol 2004;55(3):639-50.

31. Murillo MD, Plaza MA, de Pedro MJ, Arruebo MP. The effect of Ca2+ antagonists on spontaneous motility from sheep duodenum. J Pharm Pharmacol 1994;46(2):138-40.

32. Wali FA, Suer AH, Hayter A, Tugwell AC. The effect of ethanol on spontaneous contractions and on the contraction produced by periarterial nerve stimulation and by acetylcholine in the rat isolated ileum. Gen Pharmacol 1987;18(6):631-5.

33. Park JS, Choi EJ, Jeong DS, Yang HJ, Kim KP, Son KK, et al. Effects of dimyristoylphosphatidylethanol and ethanol on thickness of neuronal membrane lipid bilayers. Arch Pharm Res 2009;32(10):1469-73.

34. Fagundes DS, Gonzalo S, Arruebo MP, Plaza MA, Murillo MD. Melatonin and Trolox ameliorate duodenal LPS-induced disturbances and oxidative stress. Dig Liver Dis 2010;42(1):40-4.

35. Kelly MJ, Mathie AZ, Vallance C. A pharmacological action of vitamin E unrelated to its antioxidant capacity. Methods Find Exp Clin Pharmacol 2006;28(8):499-505.

36. Li W, Zheng T, Altura BT, Altura BM. Antioxidants prevent ethanolinduced contractions of canine cerebral vascular smooth muscle: relation to alcohol-induced brain injury. Neurosci Lett 2001;301(2):91-4.

37. Boyd AJ, Sherman IA, Saibil FG, Mamelak M. The protective effect of gamma-hydroxybutyrate in regional intestinal ischemia in the hamster. Gastroenterology 1990;99(3):860-2.

38. Aratri E, Spycher SE, Breyer I, Azzi A. Modulation of alpha-tropomyosin expression by alpha-tocopherol in rat vascular smooth muscle cells. FEBS Lett 1999;447(1):91-4. 
39. Ozer NK, Sirikci O, Taha S, San T, Moser U, Azzi A. Effect of vitamin $\mathrm{E}$ and probucol on dietary cholesterol-induced atherosclerosis in rabbits. Free Radic Biol Med 1998;24(2):226-33.

40. Matsumoto S, Leggett RE, Levin RM. The effect of vitamin E on the response of rabbit bladder smooth muscle to hydrogen peroxide. Mol Cell Biochem 2003;254(1-2):347-51.

41. Calvino Fernandez M, Parra Cid T. H. pylori and mitochondrial changes in epithelial cells. The role of oxidative stress. Rev Esp Enferm Dig 2010;102(1):41-50.

42. Solís Herruzo JA, Solís Muñoz P. Melatonin and oxidative stress. Rev Esp Enferm Dig 2009;101(7):453-9.
43. de Jongh R, Haenen GR, van Koeveringe GA, Dambros M, De Mey JG, van Kerrebroeck PE. Oxidative stress reduces the muscarinic receptor function in the urinary bladder. Neurourol Urodyn 2007;26(2):302-8.

44. Sagach VF, Scrosati M, Fielding J, Rossoni G, Galli C, Visioli F. The water-soluble vitamin E analogue Trolox protects against ischaemia/ reperfusion damage in vitro and ex vivo. A comparison with vitamin E. Pharmacol Res 2002;45(6):435-9.

45. Koyuturk M, Bolkent S, Ozdil S, Arbak S, Yanardag R. The protective effect of vitamin $\mathrm{C}$, vitamin $\mathrm{E}$ and selenium combination therapy on ethanol-induced duodenal mucosal injury. Hum Exp Toxicol 2004; 23(8):391-8 